\section{HUMANAS ESOCIAIS \\ V.8・N.1 • Abril/Maio/Junho - 2019 \\ ISSN Digital: 2316-3801 \\ ISSN Impresso: 2316-3348 \\ DOI: 10.17564/2316-3801.2019v7n3p47-56}
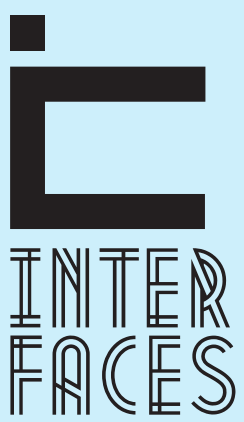

CIENTÍFICAS

\title{
DIREITO À ASSISTÊNCIA À SAÚDE PRIVADA NA CONDIÇÃO DE APOSENTADO OU DEMITIDO SEM JUSTA CAUSA
}

RIGHT TO ASSISTANCE TO PRIVATE HEALTH IN THE CONDITION OF RETIRED OR DEMISSED WITHOUT FAIR CAUSE

DERECHO A LA ASISTENCIA DE LA SALUD PRIVADA EN LA CONDICIÓN DE JUBILADO O DESPEDIDO SIN JUSTA CAUSA

Marlton Fontes Mota ${ }^{1}$ Agripino Alexandre dos Santos Filho ${ }^{2}$ Lilian Jordeline Ferreira de $\mathrm{Melo}^{3}$

\section{RESUMO}

A saúde suplementar no Brasil possui um modelo organizacional que vem alcançando as diversas camadas da sociedade, com a oferta de planos de saúde de segmento empresarial e que tem se consagrado como uma alternativa prática e acessível para grande parte da população, em especial aquela que possui vínculo empregatício. 0 crescimento do setor privado em saúde também provocou o surgimento de um vasto leque de legislações reguladoras do exercício das operadoras de saúde, trazendo à discussão os institutos protetivos para os beneficiários dos produtos ofertados pelos planos de saúde quando do rompimento do seu vínculo empregatício com as empresas contratantes dos serviços das operadoras de assistência á saúde, nesses casos, os demitidos ou exonerados sem justa causa, ou os aposentados. A pesquisa visa destacar os pontos de convergência e de divergência que traduzem a proteção dos direitos desses beneficiários à luz da legislação competente e à percepção das decisões judiciais, objetivando gerar a reflexão para o tema, utilizando a pesquisa exploratória, baseada em dados extraídos dos normativos legais, aplicando o método indutivo para a apreensão dos entendimentos jurisprudenciais que direcionam para uma aplicação mais ampla dos institutos legais, evidenciando qualitativamente as conclusões alcançadas pelos normativos jurídicos e a sua finalidade social.

\section{PALAVRAS-CHAVE}

Medicina Privada. Saúde Suplementar. Beneficiário. Contribuição. 


\section{ABSTRACT}

Supplementary health in Brazil has an organizational model that has reached the various levels of society, with the provision of health plans in the business segment, and which has become a practical and accessible alternative for a large part of the population, and especially the has an employment relationship. The growth of the private health sector has also led to the emergence of a wide range of legislation regulating the exercise of health care providers, bringing to the discussion the protective institutes for the beneficiaries of the products offered by the health plans when their employment relationship with the companies contracting the services of health care operators, and in those cases, dismissed or dismissed without just cause, or retirees. The research aims to highlight the points of convergence and divergence that translate the protection of the rights of these beneficiaries in light of the competent legislation and the perception of judicial decisions, aiming to generate the reflection to the subject, using the exploratory research, based on data extracted from the norms applying the inductive method to the apprehension of jurisprudential understandings that lead to a wider application of legal institutes, qualitatively evidencing the conclusions reached by legal norms and their social purpose.

\section{KEYWORDS}

Private Medicine. Supplementary Health. Recipient. Contribution.

\section{RESUMEN}

La salud suplementaria en Brasil posee un modelo organizacional que viene alcanzando las diversas capas de la sociedad, con la oferta de planes de salud de segmento empresarial y que se ha consagrado como una alternativa práctica y accesible para gran parte de la población y, en especial, a aquella que tiene un vínculo laboral. El crecimiento del sector privado en salud también provocó el surgimiento de un vasto abanico de legislaciones reguladoras del ejercicio de las operadoras de salud, trayendo a la discusión los institutos protectores para los beneficiarios de los productos ofrecidos por los planes de salud al rompimiento de su vínculo laboral con las empresas contratantes de los servicios de las operadoras de asistencia sanitaria, y en esos casos, los despedidos o exonerados sin justa causa, o los jubilados. La investigación pretende destacar los puntos de convergencia y de divergencia que traducen la protección de los derechos de esos beneficiarios a la luz de la legislación competente y la percepción de las decisiones judiciales, con el objetivo de generar la reflexión para el tema, utilizando la investigación exploratoria, basada en datos extraídos de los normativos de acuerdo con el método inductivo para la aprehensión de los entendimientos jurisprudenciales que 
dirigen hacia una aplicación más amplia de los institutos legales, evidenciando cualitativamente las conclusiones alcanzadas por los normativos jurídicos y su finalidad social.

\section{PALABRAS CLAVE}

Medicina privada. Salud suplementaria. Beneficiario. Contribución.

\section{INTRODUÇ̄̃̃O}

Inafastável o fato de que o surgimento da chamada medicina privada no Brasil alterou significativamente o cenário nacional da prestação da assistência à saúde que passou a ter uma projeção mais dinâmica e ampliada no sentido de atendimento às diversas camadas sociais, depois da promulgação da Carta Constitucional de 1988, que inseriu nos seus artigos 197 e 199 a previsão normativa para a saúde suplementar, viabilizando a participação da iniciativa privada no mercado de saúde.

Da criação dos diversos modelos de assistência privada à saúde, o plano coletivo firmado entre operadora de saúde privada e as diversas entidades contratantes, que são ofertados aos empregados dessas empresas, se submete às previsões contidas na Lei n 9656/96, que consolida o direito do beneficiário de plano de saúde coletivo empresarial à assistência à saúde, direitos estes que lhe são preservados, inclusive nas situações em que sofra uma demissão ou uma exoneração da sua função/ cargo sem justa causa, ou ainda quando decida se aposentar.

A proposta da pesquisa é a de evidenciar essas circunstâncias protetivas do empregado que se enquadra nas condições comentadas, que é uma grande preocupação do beneficiário do plano de saúde, especialmente nos casos em que necessita da assistência para a manutenção da sua saúde e a dos seus familiares que fazem parte do seu rol de dependentes perante o plano.

O empregado que contrata esse segmento de saúde privada tem dúvidas e questionamentos a respeito dos seus direitos e garantias que são previstos nos normativos inerentes, mas que pendem por uma melhor interpretação legal. Para alcançar o objetivo primordial da pesquisa buscou-se fazer uma análise dos institutos legais existentes a respeito do tema, além de conferir as recentes decisões judiciais relativas à condição do empregado exonerado, demitido ou aposentado e a continuidade da assistência à saúde prevista na contratação do seu plano de saúde coletivo.

Por meio da pesquisa exploratória, que tem o intuito de promover um maior estreitamento do trabalho com o objeto pesquisado, foi elaborado um levantamento bibliográfico dos conteúdos normativos e doutrinários, abordando a temática central de forma descritiva e qualitativa. Sendo pontual destacar que, além das garantias outras previstas na legislação brasileira, a permanência do empregado demitido, exonerado ou aposentado no plano de saúde tem sido objeto de divergências de interpretações, e que serão devidamente apresentadas no presente trabalho, possibilitando uma maior reflexão sobre o tema e o seu alcance para uma garantia de assistência à saúde digna. 


\section{OS PLANOS DE SAÚDE COLETIVOS E A A.N.S.}

De acordo com Agência Nacional de Saúde Suplementar (ANS)4 , criada pela Lei nº 9.961/200, os planos de saúde coletivos são classificados em dois tipos, os chamados empresariais que oferecem a assistência à saúde em razão do vínculo empregatício dos funcionários da empresa contratante e os planos coletivos por adesão, que são aqueles contratados por pessoas jurídicas de caráter profissional.

O papel institucional da Agência Nacional de Saúde Suplementar é citado por Seguin (2005, p. 131), destacando sobre a preponderância dos seus dispositivos a respeito dos planos de saúde, quando houver o conflito de atribuições daquela entidade com o Conselho Regional de Medicina, cuja meta reguladora busca a independência técnica, prescindindo da ingerência política, para alcançar um ponto ótimo ou de equilíbrio que atenda ao interesse público.

Esclarece a ANS que o plano de saúde coletivo empresarial se diferencia daquele plano de saúde individual, porque nesse último o interessado em contratar a assistência prestada poderá fazê- lo diretamente com a operadora de saúde na condição de pessoa física, dispensando a vinculação a uma entidade empregadora específica.

A definição do plano de saúde coletivo empresarial está prevista na Resolução Normativa - RN nº 195 (ANS), datada de 14 de julho de 2009, no seu artigo 5º por sua vez, os planos coletivos por adesão são definidos no artigo $9^{\circ}$ da citada Resolução.

Cabe destaque, sendo o plano de saúde uma categoria diferenciada no que diz respeito a sua natureza jurídica, apesar de ser considerado um típico contrato de consumo, o entendimento da doutrina que aponta o fato de que, embora se aplique aos referidos contratos as normas de proteção do CDC. Essa postura é explicada por Reinaldo Filho (2004, p. 2), ao enfatizar o fato de que o "plano coletivo empresarial de assistência à saúde" não se enquadra em nenhuma das modalidades contratuais típicas, por revestir características próprias.

A grande discussão que povoa a relação do consumidor dos produtos ofertados pelos planos de saúde coletivos está na legitimidade desse consumidor para o exercício do seu direito de ação para postular seus direitos contra a operadora de assistência à saúde, condição esta que já obteve a apreciação do Superior Tribunal de Justiça em vários dos seus julgados.

Nesse sentido, visando ampliar a proteção dos direitos dos usuários dos planos de saúde coletivos, tramita no Senado Federal o Projeto de Lei $n^{0} 20^{5}$, de 2016, com proposta para alterar a Lei $n^{0} 9.656$, que dispõe sobre os planos e seguros privados de assistência à saúde, visando garantir a legitimidade

4 AAgência Nacional de Saúde Suplementar (ANS) é a agência reguladora vinculada ao Ministério da Saúde responsável pelo setor de planos de saúde no Brasil (http://www.ans.gov.br/aans/quem-somos).

5 PARECER DA COMISSÃO DE MEIO AMBIENTE, DEFESA DO CONSUMIDOR E FISCALIZAÇÃO E CONTROLE, sobre o Projeto de Lei do Senado $n^{\circ} 20$, de 2016, do Senador Fernando Bezerra Coelho, que altera a Lei $n^{\circ} 9.656$, de 3 de junho de 1998, que dispõe sobre os planos e seguros privados de assistência à saúde, para garantir aos consumidores de plano de saúde coletivo empresarial ou coletivo por adesão, se violado algum direito ou interesse juridicamente protegido, legitimidade ativa ad causam contra Plano Privado de Assistência à Saúde. 
ativa ad causam dos consumidores contra planos de assistência à saúde, especialmente aqueles enquadrados na condição de beneficiários de contratos coletivos.

\section{OS DIREITOS E GARANTIAS AO EX-EMPREGADO SOB O OLHAR DA LEI $9.656 / 98$ E DA JU- RISPRUDÊNCIA}

A Lei n 9656/98 traz no seu bojo orientações normativas para a fiscalização, autorização de funcionamento das operadoras de planos privados de assistência à saúde, instituição de planos-referência, comercialização de produtos, dentre outros, e da mesma forma, a citada legislação preconiza garantias protetivas para o consumidor que contribui para os planos privados de assistência à saúde e que possui vínculo empregatício com a entidade contratante do plano de saúde, tem a proteção dos seus direitos no caso de rescisão ou exoneração do contrato, conforme se lê do artigo 30 da citada lei, a saber:

Art. 30. Ao consumidor que contribuir para produtos de que tratam o inciso I e o $\$ 1^{\circ}$ do art. $1^{\circ}$ desta Lei, em decorrência de vínculo empregatício, no caso de rescisão ou exoneração do contrato de trabalho sem justa causa, é assegurado o direito de manter sua condição de beneficiário, nas mesmas condições de cobertura assistencial de que gozava quando da vigência do contrato de trabalho, desde que assuma o seu pagamento integral.

A proteção anunciada no artigo 30 da Lei no 9656/98 traz algumas ressalvas e orientações específicas que deverão ser observadas pelo ex-empregado demitido ou exonerado sem justa causa, para o enquadramento do benefício de manter-se vinculado ao plano de saúde contratado.

Preconiza a Resolução Normativa - RN 279/2011 da ANS, que o ex-empregado demitido ou exonerado sem justa causa ou aposentado deverá ser comunicado de forma inequívoca "sobre a opção de manutenção da condição de beneficiário de que gozava quando da vigência do contrato de trabalho" (art. 10, P.U.), e terá o prazo de 30 dias para exercer o seu direito de opção em manter-se vinculado ao plano de saúde, prazo este que é contado a partir do recebimento da comunicação do empregador.

\subsection{O PAGAMENTO DA CONTRIBUICÕ̃ MENSAL PELO CO-PATROCINADOR}

À leitura do artigo 30 da Lei no 9656/98, supra destacado, verifica-se que o consumidor tem assegurado o seu direito de manter-se vinculado ao plano de saúde, assumindo o pagamento integral da contribuição mensal para o plano, que significa dizer que a sua contribuição abrangerá a parte patronal da mensalidade, que era evidenciada quando da sua condição de empregado ou servidor ativo. De igual importância, a previsão do texto legal exprime sobre a necessária condição de copatrocinador do consumidor na mensalidade devida ao plano, prevendo o pagamento da contribuição por parte da empresa que mantinha o vínculo com o empregado, e a contrapartida deste, com a copatrocínio sobre os valores mensais da contribuição para o plano. 
Em recente decisão exarada em data de 2 de agosto de 2017, no Agravo Interno no Resp no 1.651.060-SP, o Superior Tribunal de Justiça novamente enfrentou o tema a respeito da assunção do pagamento integral da parcela mensal destinada ao plano de saúde, que deverá ser assumida pelo ex-empregado demitido sem justa causa ou aposentado, explicando que "nos planos de saúde custeados exclusivamente pelo empregador não há direito de permanência do ex-empregado aposentado ou demitido sem justa causa como beneficiário".

Em resumo, essa é uma condição obrigatória que exige a contribuição por parte do consumidor ao plano de saúde, contribuição esta que se apresenta diferentemente da parcela destinada à coparticipação decorrente do percentual de pagamento sobre uso dos produtos ofertados pela operadora (internamentos, consultas, procedimentos etc.).

Embora o Superior Tribunal de Justiça (STJ) já tenha se posicionado a respeito do tema, e havendo previsão legal no artigo $30, \S 6^{\circ}$ da Lei $n^{\circ} 9656 / 98$, cumpre evidenciar que alguns tribunais estaduais pronunciavam entendimento contrário, ao consolidar que a ausência de contribuição na mensalidade não afastaria o direito de manutenção do plano de saúde pelo ex-empregado demitido sem justa causa, demonstrando que o dissenso de interpretações conceituais da Lei nº 9656/98 é pontual.

Portanto, o plano de saúde custeado integralmente pela empresa não garante ao ex-empregado a continuidade e a manutenção da referida assistência à saúde se o beneficiário não contribuiu mensalmente para a operadora, e por não se tratar de salário in natura, conforme preconiza a Consolidação das Leis do Trabalhio (CLT), no seu artigo 458, §2 , inciso IV, não elide a exigência prevista no artigo 30 da Lei no 9656/98.

Com relação ao período previsto para a manutenção do consumidor no plano de saúde contratado, na condição de beneficiário, a Lei no 9656/98 compreende que esse prazo é de 1/3 (um terço) do tempo em que permaneceu vinculado ao plano de saúde, estendendo-se os efeitos aos sucessores do beneficiário-titular, sendo-lhes assegurado o prazo mínimo de 6 (seis) meses e o prazo máximo de 24 (vinte e quatro) meses, em conformidade com o parágrafo $1^{\circ}$ do artigo 30 , da referida Lei, sendo esse direito assegurado aos dependentes do consumidor, em caso de morte deste $\left(\S 2^{\circ}\right)$.

0 direito à manutenção do plano de saúde é restritivo "aos contratos que foram celebrados após $1^{\circ}$ de janeiro de 1999, ou que foram adaptados à Lei n 9.656, de 1998”, orientação esta prevista no artigo $3^{\circ}$ da Resolução Normativa - RN n² 279/2011 da ANS.

\subsection{A ASSUNÇÃO DE NOVO EMPREGO E A EXTINÇão DO VÍNCULO COM A OPERADORA DE SAÚdE}

Impõe-se destacar que a condição prevista na Lei no 9656/98 (art. 30), mencionada alhures, deixará de existir caso o consumidor seja admitido em novo emprego ( $\$ 5^{\circ}$, artigo 30) e essa previsão tem sido objeto de apreciação do judiciário brasileiro, com considerações que adentram ao entendimento preconizado pelo parágrafo $5^{\circ}$ anotado.

Evidencia-se o fato de que o inciso III, do artigo $2^{\circ}$, da RN 279/2011 (ANS), explicita sobre admissão do ex-empregado em novo emprego e a condição expressa para a perda do direito de manter-se vinculado ao plano de saúde anteriormente contratado, prevendo que: "novo emprego: novo vínculo profissional que possibilite o ingresso do ex-empregado em um plano de assistência a saúde coletivo empresarial, coletivo por adesão ou de autogestão". 
Nesta esteira de raciocínio, cumpre analisar o fato de que ao expor no artigo 30, a Lei nº 9656/98 determina que o beneficiário deve ser mantido "nas mesmas condições de cobertura assistencial de que gozava quando da vigência do contrato de trabalho" e isso significa que ao ex-empregado deve ser concedida a mesma cobertura da assistência, mesma área geográfica, mesma rede de prestadores com o rol de procedimentos e acomodações previstas pelo seu contrato com o plano de saúde que gozava, de acordo com o artigo $2^{\circ}$, II da Resolução Normativa 279/2011 (ANS).

Questiona-se, portanto, se o direito de manutenção no plano de saúde assegurado ao empregado demitido ou exonerado, ainda poderá ser afastado caso ele assuma novo emprego, mesmo sob a condição diferenciada existente entre a oferta de produtos do novo plano de saúde em relação àquela realizada e mantida pela operadora anterior, consolidando-se numa drástica redução qualitativa da assistência à saúde em prejuízo do consumidor e dos seus dependentes. Afinal, a legislação especifica que o ex-empregado deverá ser mantido nas “mesmas condições de cobertura assistencial" ofertada pelo plano de saúde, quando exercente das atividades laborais perante a empresa contratante dos serviços da operadora de saúde.

Há um consenso no entendimento de que se o plano de saúde oferecido pelo empregador ao ex-empregado demitido sem justa causa deixar de existir, haverá a possibilidade da migração do seu contrato com a operadora para contratar um plano individual, afastando-se o cumprimento das carências já cumpridas e desde que a operadora em questão comercialize plano individual e familiar.

É previsto pela Resolução Normativa - RN 279/2011 da ANS, que o empregador pode manter o ex-empregado demitido ou exonerado sem justa causa ou aposentado "no mesmo plano privado de assistência à saúde em que se encontrava quando da demissão ou exoneração sem justa causa ou aposentadoria" (artigo 13, I), ou ainda "contratar um plano privado de assistência à saúde exclusivo para seus ex-empregados demitidos ou exonerados sem justa causa ou aposentados” (artigo 13, II). Nesse caso, a referida Resolução Normativa orienta que o plano de saúde deverá ser oferecido pelo empregador, e em regra com a mesma operadora de saúde, mediante contrato coletivo empresarial e na mesma segmentação e cobertura (artigo 18).

Novamente, percebe-se que a intenção do legislador é a de proporcionar ao ex-empregado a manutenção das condições contratadas com a operadora de saúde, que possibilite idêntica segmentação da rede de assistência à saúde, no modelo de acomodação e efetivamente que cubra a área geográfica de abrangência, ainda que seja ofertada ao empregado uma opção mais acessível, de acordo com a legislação pertinente, mas, essa legislação admite que não poderá haver decréscimo de qualidade do produto e serviços ofertados pela operadora.

Portanto, seria lógica a conclusão de que sob a oferta de plano de saúde no novo emprego assumido pelo ex-empregado demitido e/ou exonerado sem justa causa, não poderia haver a imposição na aplicação dos termos previstos na legislação comentada, cessando o direito de permanência do ex-empregado no plano anteriormente ofertado sem observar o critério de qualidade desse novo plano. E caso aplique-se o instituto legal, deverá ser observada a garantia de idêntica cobertura e segmentação na oferta do novo plano de saúde, para que não seja qualitativamente inferior nos quesitos: acomodações hospitalares, área de abrangência, dentre outros. 


\section{OS DIREITOS OUTORGADOS AO EMPREGADO APOSENTADO}

A legislação pátria ampliou a sua rede protetiva para abarcar os direitos do empregado aposentado em manter-se vinculado ao plano de saúde coletivo, para o qual contribuiu durante a manutenção do pacto laboral, isto de acordo com as prerrogativas insertas na Lei no $9.656 / 1998$, que no seu artigo 31 preconiza que:

Ao aposentado que contribuir para produtos de que tratam o inciso I e o $\S 1^{\circ}$ do art. $1^{\circ}$ desta Lei, em decorrência de vínculo empregatício, pelo prazo mínimo de dez anos, é assegurado o direito de manutenção como beneficiário, nas mesmas condições de cobertura assistencial de que gozava quando da vigência do contrato de trabalho, desde que assuma o seu pagamento integral.

Existem diversos argumentos sobre o fato de que a permanência do empregado aposentado no plano de saúde coletivo, em conformidade com a legislação competente, traz um significativo aumento da sinistralidade do contrato em prejuízo à empresa contratante da operadora de saúde. Essas afirmações se pautam no perfil do ex-empregado aposentado que em regra tem idade avançada e que por uma questão de natural fragilidade na sua saúde, tem um maior consumo dos produtos ofertados pelo plano de saúde e o consequente aumento do custo operacional na manutenção desse beneficiário, mesmo com a sua assunção da integralidade na contribuição mensal que é vertida para operadora de assistência à saúde.

O prazo mínimo de 10 (dez) anos previstos pela legislação específica, destacado alhures, é balizador para garantir a permanência do aposentado no plano de saúde indefinidamente, enquanto a empresa mantiver a contratação com a operadora de saúde que presta atendimento aos empregados ativos da citada empresa.

Caso o período evidenciado acima seja inferior ao prazo mínimo de 10 (dez) anos de contribuição pelo aposentado, a Lei n 9656/98, no parágrafo primeiro do seu artigo 31, orienta que: "é assegurado o direito de manutenção como beneficiário, à razão de um ano para cada ano de contribuição, desde que assuma o pagamento integral do mesmo".

Em boletim informativo (2016) lançado pela Agência Nacional de Saúde Suplementar (ANS), ficou contextualizado o exemplo prático para esclarecer a condição de empregado aposentado e que não cumpriu o prazo mínimo de 10 (anos) vinculado ao plano de saúde, assim dispondo:

Exemplo 1: o trabalhador ficou cinco anos pagando pelo plano. Poderá ficar com o plano por cinco anos após se aposentar.

Exemplo 2: o trabalhador ficou 10 meses pagando pelo plano. Poderá permanecer com o plano por 10 meses.

De acordo com o documento expedido pela ANS, acima retratado, o trabalhador que não alcançar o prazo mínimo de 10 (dez) anos, prestando serviços para determinada empresa, não terá o direito à 
vitaliciedade da assistência à saúde prestada pela operadora, sendo explicado que o aposentado poderá permanecer no plano pelo prazo que ficou vinculado à empresa que prestou serviços, conforme cálculos acima destacados.

\subsection{AS CONDICÕ̃ES PREVISTAS PARA A PRESERVAÇ̃̃O DOS DIREITOS DO APOSENTADO}

À clarividência dos termos adotados pelos legisladores no parágrafo terceiro, artigo 31 da Lei $n^{\circ}$ $9656 / 1998$, orientando sobre a aplicação das condições exigidas nos parágrafos $2^{\circ}$ ao $6^{\circ}$ do artigo 30, da referida Lei, trazem a possibilidade da extensão dos direitos outorgados ao aposentado ao seu grupo familiar, isto indicado para aqueles dependentes já inscritos no plano de saúde à época da vigência do contrato de trabalho. Cabe destacar que não há impedimento legal para a inclusão de novos dependentes que venham a fazer parte do grupo familiar do titular depois do evento aposentadoria, a exemplo do nascimento de filhos ou da constituição de novo casamento.

Com relação à inclusão de dependentes do beneficiário, a Resolução Normativa - RN nº 279/2011 (ANS) conclui pela possibilidade dessa ocorrência, inclusive permitindo ao ex-empregado que condicione a delimitação do grupo familiar que deverá permanecer vinculado ao plano de saúde, de acordo com o artigo $7^{\circ}$ e parágrafos da citada Resolução.

Em caso de morte do ex-empregado demitido ou exonerado sem justa causa, ou aposentado, fica garantido o direito de permanência dos seus dependentes cobertos pelo plano de saúde, conforme estabelece o artigo 30, $\S 3^{\circ}$ da Lei nº 9656/98, e é confirmado no artigo $8^{\circ}$ da Resolução Normativa RN n 279/2011 da ANS.

\subsection{DA CONTAGEM DO PRAZO PARA O TEMPO DE PERMANÊNCIA}

A legislação é clara sobre os prazos exigidos e que deverão ser cumpridos pelo empregado aposentado e que configurarão o limite de tempo da sua permanência no plano de saúde, que pode ocorrer de forma vitalícia caso tenha contribuído 10 (dez) anos ou mais para a operadora de assistência à saúde (artigo 31, caput, Lei n 9656/98), ou se o aposentado contribuiu por um período inferior a 10 (dez) anos, sendo-lhe assegurada a manutenção "à razão de um ano para cada ano de contribuição, desde que assuma o pagamento integral do mesmo" (art. 30, §1º).

Um ponto de grande relevância é o de identificar se no prazo de contribuição por parte do aposentado deverá ser observada a contagem de tempo ininterrupto (continuado) ou se poderia ser fracionado (descontínuo), aplicando-se neste último a soma dos períodos em que o empregado trabalhou para a empresa, nas situações de recontratação. A legislação competente assegura a exigência de que deve haver a contribuição para o plano de saúde, destacando o marco temporal maior ou menor de 10 (dez) anos, sem predizer sobre a forma da contagem desse prazo, e a esse respeito alguns dos tribunais de justiça brasileiros têm decidido com o entendimento pela contagem ininterrupta, conforme se lê:

Ementa: Apelação - Plano de saúde - Manutenção da Autora no plano de saúde nas mesmas condições em que gozava quando da vigência do contrato de trabalho - Apli- 
cação do artigo 31 da Lei no 9.656 /98 - Contribuição por mais de dez anos ininterruptos para o plano de saúde empresarial - Recurso improvido. TJ-SP - Apelação APL 10072221420148260292 SP 1007222-14.2014.8.26.0292 (TJ-SP). Data de publicação: 18/02/2016 (Grifos nossos).

Imperioso destacar que a aplicação da regra de contagem do prazo de forma ininterrupta, decorrente do entendimento jurisprudencial, pode evidenciar um prejuízo ao direito de manutenção do ex-empregado aposentado no plano de saúde, haja vista a possibilidade de esse profissional ser recontratado em diversas oportunidades pela empresa pagadora, situação esta que não seria considerada anormal a depender da função exercida pelo empregado. Nesse caso, a sua contribuição mensal para o plano, exercida de forma descontinuada, poderia sim consolidar o total de tempo necessário para alcançar a prerrogativa de permanência vitalícia, se somados todos os períodos trabalhados para a mesma empresa em momentos distintos e ser alcançado o prazo legal de 10 (dez).

As interpretações diversas podem ser deflagradas pela ausência de uma definição mais explícita da legislação, a exemplo do empregado aposentado que exerce funções laborativas depois da aposentadoria, que para o Superior Tribunal de Justiça não perde a condição de aposentado, assim definido nos autos do Recurso Especial n 1.371.271 - RJ (2013/0079607-8), no voto da relatora Ministra Nancy Andrighi que assim se posicionou:

0 art. 31 da Lei 9.656/98 não evidencia, de forma explícita, que a aposentadoria deve dar-se posteriormente à vigência do contrato de trabalho, limitando-se a indicar a figura do aposentado - sem fazer quaisquer ressalvas- que tenha contribuído para o plano de saúde, em decorrência do vínculo empregatício.

A posição adotada pela ilustre relatora do REsp acima destacado, a Ministra Nancy Andrighi, denota o fato de que a Lei n⿳0 9656/98 em diversos pontos permite a ampliação do entendimento preconizado pelos seus artigos, justamente por não enfatizar o alcance dos conceitos e dos limites impostos pela hermenêutica das prerrogativas insertas no seu bojo, resumindo-se em prejuízos para os ex-empregados e em especial aos aposentados que poderiam alcançar a vitaliciedade da assistência à saúde, numa interpretação mais humanizada da legislação competente.

\section{CONCLUSÃO}

É patente a formação do vínculo contratual entre os consumidores dos produtos ofertados pelos planos de saúde e a assistência médico-hospitalar que estes oferecem, dessa comercialização de produtos a legislação preconiza garantias protetivas para o consumidor, especialmente para aquele que contribui para os planos privados de assistência à saúde e que possui vínculo empregatício com a entidade contratante do citado plano. 
Essas garantias protetivas aos direitos do beneficiário do plano de saúde empresarial estão explicitadas na Lei n 9656/98, incluindo-se o direito de manutenção no plano de saúde assegurado ao empregado demitido ou exonerado, e ao aposentado.

Porém, registra-se na pesquisa a crítica sobre o alcance na interpretação dos conceitos e dos limites impostos pela legislação, permitindo-se a insurgência de alguns dissensos na compreensão dos seus artigos pela jurisprudência pátria, até que se consolide um único raciocínio ou que se defina essa unicidade perante os tribunais superiores, o direito do usuário ex-empregado, demitido ou exonerado sem justa causa e do empregado aposentado, terão sofrido uma diversidade de máculas limitativas da plenitude nas garantias previstas pelo legislador para a sua assistência à saúde.

A pesquisa justifica a importância do seu objeto, pois, promove a reflexão sobre a importância da interpretação ampliativa da legislação de planos privados em saúde pelo poder judiciário, afastando-se o surgimento de possíveis obstáculos à ampla garantia da dignidade do titular do plano privado de saúde, em especial do empregado aposentado.

\section{REFERÊNCIAS}

BRASIL. Agência Nacional de Saúde Suplementar (ANS). Superior Tribunal de Justiça (STJ). Agravo Interno no Resp no 1.651.060-SP. Disponível em: https://stj.jusbrasil.com.br/ jurisprudencia/485091753/agint-no-recurso-especial-agint-no-resp-1651060-sp-2017-00199269?ref=topic_feed. Acesso em: 19 mar.2018.

BRASIL. Agência Nacional de Saúde Suplementar (ANS). Lei 9.656, de 03 de junho de 1998. Dispõe sobre os planos e seguros privados de assistência à saúde. Disponível em: www.planalto.gov.br. Acesso em: 20 mar.2018.

BRASIL. Agência Nacional de Saúde Suplementar (ANS). Lei 9.961, de 28 de janeiro de 1999. Cria a Agência Nacional de Saúde Suplementar - ANS e dá outras providências. Disponível em: www. planalto.gov.br. Acesso em: 20 mar. 2018.

BRASIL. Agência Nacional de Saúde Suplementar (ANS). Resolução Normativa - RN nº 195, de 14 de julho de 2009. Dispõe sobre a classificação e características dos planos privados de assistência à saúde, regulamenta a sua contratação, institui a orientação para contratação de planos privados de assistência à saúde e dá outras providências. Disponível em: http://www.ans.gov.br/component/ legislacao/. Acesso em: 21 mar.2018.

BRASIL. Agência Nacional de Saúde Suplementar (ANS). Resolução Normativa - RN n 279, de 24 de novembro de 2011. Dispõe sobre a regulamentação dos artigos 30 e 31 da Lei no 9.656, de 3 de junho de 1998, e revoga as Resoluções do CONSU nº 20 e 21, de 7 de abril de 1999. Disponível em: 
http://www.ans.gov.br/component/legislacao/?view=legislacao\&task=TextoLei\&format=raw\&id=MT g50A. Acesso em: 21 mar.2018.

BRASIL. Agência Nacional de Saúde Suplementar (ANS). Recurso Especial n 1.371 .271 - RJ (2013/0079607-8). Julgado em 02.02.2017. Disponível em: https://ww2.stj.jus.br/processo/revista/ documento/mediado/?componente=ITA\&sequencial=1566986\&num_registro=201300796078\&data =20170210\&formato=PDF. Acesso em: 26 mar. 2018.

CONSUMO E PLANOS DE SAÚDE. Boletim Informativo. Agência Nacional de Saúde Suplementar (ANS). fev. 2016. ano 1, n. 2.

REINALDO FILHO, Demócrito. A natureza jurídica do plano de saúde coletivo - sua repercussão em termos de abusividade da cláusula que permite o reajuste por sinistralidade. Âmbito Jurídico. Disponível em: http://www.ambito-juridico.com.br/site/index.php?n_link=revista_artigos_ leitura\&artigo_id=4142. Acesso em: 24 mar. 2018.

SEGUIN, Élida. Plano de saúde. Rio de Janeiro: Lúmens Júris, 2005. 
1 Doutorando em Educação pela Universidade Tiradentes - UNIT/SE; Mestre em Educação pela Universidade Tiradentes - UNIT; Especialista em Direito Processual Civil pela Universidade Unyanha (BA); Coordenador de projetos de iniciação científica PROVIC/Unit, pesquisador-líder do Grupo de Pesquisa "Gênero, Direitos Humanos e Diversidade Sexual”, CNPq. e-mail: prof.marlton@gmail.com

2 Doutor em Desenvolvimento e Meio Ambiente - UFS/PRODEMA; Mestre em Desenvolvimento e Meio Ambiente - UFS/ PRODEMA; Líder do Grupo de Pesquisa "Direitos Humanos e Bioética - DIHB. E-mail: agripino.alexandre@gmail.com

3 Mestranda em Direitos Humanos pela Universidade Tiradentes - UNIT/SE; Pós-graduada em Direito Tributário pela Universidade Candido Mendes (RJ); Bacharela em Direito pela Universidade Tiradentes - UNIT/SE.

E-mail: Lilianjfmelo@hotmail.com

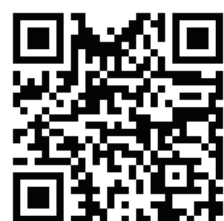

A autenticidade desse artigo pode ser conferida no site https://periodicos. set.edu.br

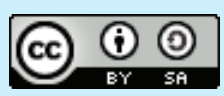

Este artigo é licenciado na modalidade acesso abertosob a Atribuição-Compartilhalgual CC BY-SA

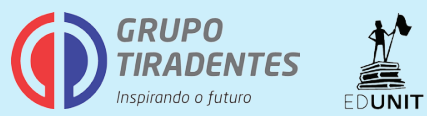


